\title{
Submitted: Optimization of diagnostic ultrasonography Accepted: of the gallbladder based on own experience and literature
} 13.11.2019

Published: 31.03.2020

Keywords gallbladder, lesions, scanning technique, ultrasonography, differentiation

\author{
Andrzej Smereczyński, Katarzyna Kołaczyk, Elżbieta Bernatowicz
}

Self-education Ultrasonographic Association, Department of Genetics and Pathomorphology, Pomeranian Medical University, Szczecin, Poland

Correspondence: Andrzej Smereczyński, Self-education Ultrasonographic Association at the Department of Genetics and Pathomorphology, Pomeranian Medical University, Połabska 4, 70-115 Szczecin; tel.: +4891454 22 17, e-mail: andrzejsmereczynski@onet.eu

DOI: $10.15557 / \mathrm{JoU} .2020 .0006$

\begin{abstract}
Although transabdominal imaging of the gallbladder has become a gold standard, new light should be shed on some aspects, which will prove useful in everyday practice. Therefore, based on our own experience and the available literature, we would like to draw attention to those elements of gallbladder ultrasound imaging which may increase its diagnostic efficacy. The paper draws attention to the difficulty in assessing certain anatomical structures, such as the inferior wall, the bottom and the region of the neck of the gallbladder, and offers ways to improve their imaging. We also emphasized the negative effects of duodenal and transverse colon (along with their contents) adhesion to the bottom of the gallbladder on the correct diagnosis. Due to the importance of size in the management strategy for detected gallbladder polyps, we suggest their measurement on an image enlarged with the zoom function. This technique also allows for an accurate assessment of the shape and echostructure of these lesions. An enlarged image of a polyp makes it possible to trace its behavior in time. We also remind that the hepatic wall of the gallbladder is the only site allowing for a reliable wall thickness measurement. We also pointed to the importance of changing patient's position when assessing the mobility and the nature of lesions. Altering patient's position during examination may help detect anomalies in the form of a floating gallbladder, which may promote its torsion. Finally, pathologies whose diagnosis may be facilitated by color-coded blood flow imaging are also presented. The issues discussed in this paper are only a fraction of problems faced by an ultrasound operator in the field of gallbladder diagnostic imaging. However, the proposed ultrasound approaches should help solve some of these problems in everyday practice.
\end{abstract}




\section{Introduction}

The introduction of harmonious and spatially complex imaging with a simultaneous reduction of image speckles have contributed to significant advances in gallbladder ultrasonography. Furthermore, optimization of this technique was achieved by constructing high-resolution broadband transducers with 3D and 4D options for organ imaging. This diagnostic arsenal was further enriched with endoscopic, laparoscopic and contrast-enhanced ultrasound (CEUS), as well as elastography and automatic organ segmentation, which was achieved using a special algorithm ${ }^{(1-11)}$. Ultrasonography has long been a method allowing for precise cytological diagnosis of lesions by means of transabdominal and endoscopic ultrasound-guided fine needle aspiration biopsy ${ }^{(12-14)}$. Finally, the technique has gained acceptance as a treatment method for acute cholecystitis in patients disqualified from cholecystectomy by percutaneous or endoscopic aspiration of the infected content or by a temporary gallbladder drainage ${ }^{(14-16)}$.

Digital ultrasonography with a variety of options to improve the image and different modes of color-coded blood flow is usually used in daily practice. In our opinion, the best protocol for gallbladder ultrasonography was presented by Hertzberg and Middleton, the authors of "Ultrasound: the requisites"(17). A comprehensive examination of this organ involves scanning in various positions (supine, prone, oblique and upright). This allows for almost complete visualization of gallbladder walls and content, as well as the mobility of lesions inside the gallbladder. In this paper, we would like to draw attention to some elements of gallbladder ultrasound, which may increase its diagnostic efficacy in everyday clinical practice, based on our own experience and the available literature.

To begin with, it seems important to specify which parts of the gallbladder are difficult to evaluate.

\section{Anatomical and topographic conditions}

Figure 1 shows an optimal view of the gallbladder in two cross-sections in upright position. This image was obtained owing to the liver, which is an acoustic window for all parts of the gallbladder, including the fundus. The

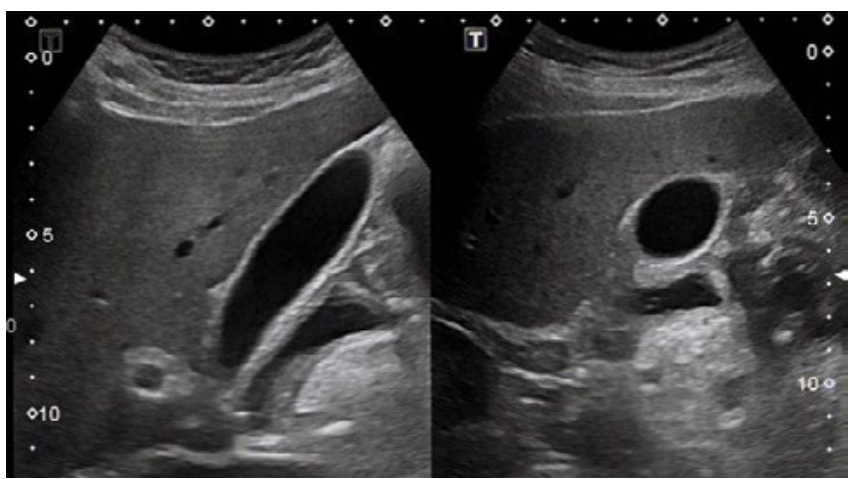

Fig. 1. An entire gallbladder is clearly visible in two cross-sections due to hepatic acoustic window for all its parts

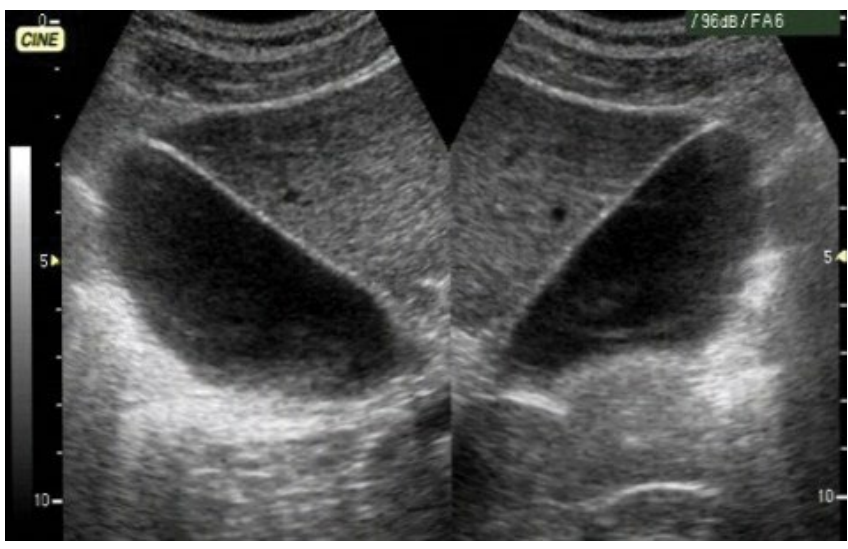

Fig. 2. Two oblique cross-sections of the gallbladder. Its walls may be assessed only when contacting the liver. Gas in the duodenal bulb causes distinct reflections, which make it impossible to assess the gallbladder wall at this site

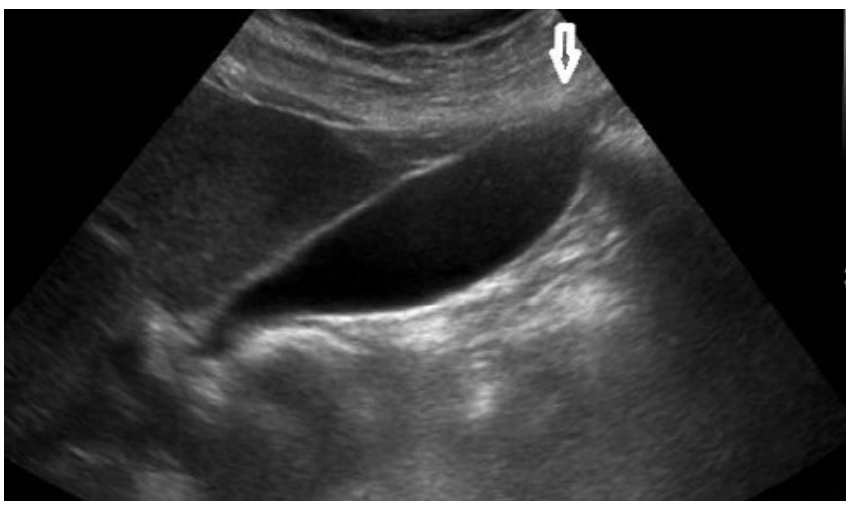

Fig. 3. The arrow indicates the gallbladder fundus, which is difficult to assess as it is not covered by the liver

posterior wall of the gallbladder closely adheres to the duodenal bulb, which is filled with liquid in this case. The image may be unclear due to the presence of gas generating reflections in the gallbladder, which mimic biliary sludge. This acoustic effect also blurs the outline of the gallbladder wall in this region. Changing patient's position allows for accessing the previously inaccessible wall segments (Fig. 2). A situation when the gallbladder fundus protrudes beyond the border of the liver is another common anatomical variant (Fig. 3). In such cases, when a convex transducer with a mean frequency of $3.5 \mathrm{MHz}$ is used, the image of the gallbladder fundus becomes blurred and, consequently, lesions in this location may be overlooked. This is the most common location of focal adenomyomatosis, which is found in 1-9\% of cholecystectomy specimens ${ }^{(18)}$. Our observations indicate that ultrasonography often fails to detect this type of pathology at this site (Fig. 4 A and Fig. 4 B). A linear 7-12 MHz transducer allows for obtaining a clearer image of the gallbladder fundus in patients without overweight or adiposity (Fig. 5 and Fig. 6). Significant diagnostic difficulties occur in the case of pathological lesions located in the neck region in patients with a large anteroposterior epigastric size. Imaging improvement may be expected after moving the focus to the ROI (Fig. 7). However, it should be kept 

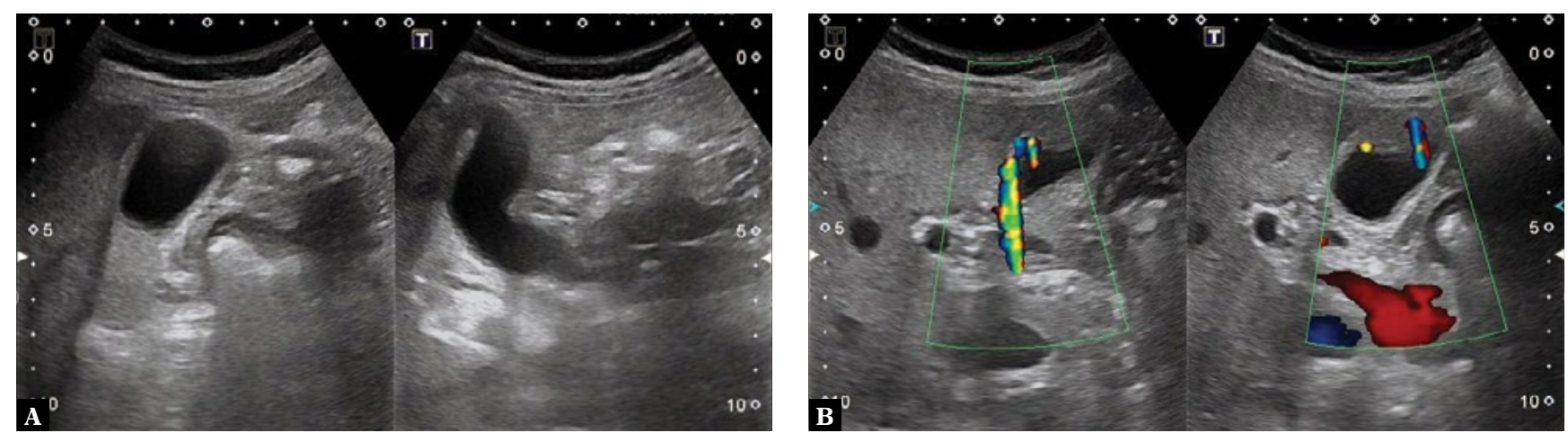

Fig. 4. Gallbladder. A. Two typical cross-sections, with no detectable lesions. B. The same case. Focusing on the assessment of the gallbladder fundus allowed to identify signs of focal adenomyomatosis

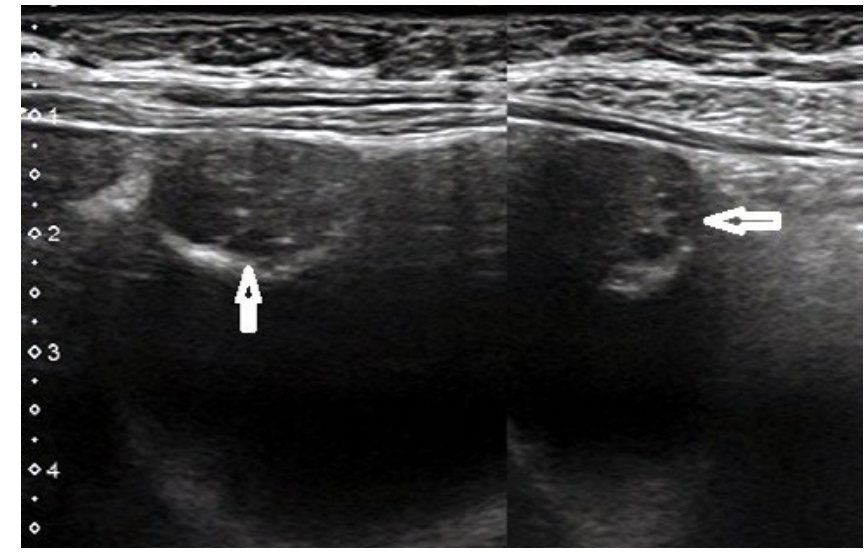

Fig. 5. An image of adenomyomatosis in the gallbladder fundus, obtained with a linear transducer. The arrows point to the Rokitansky-Aschoff sinuses

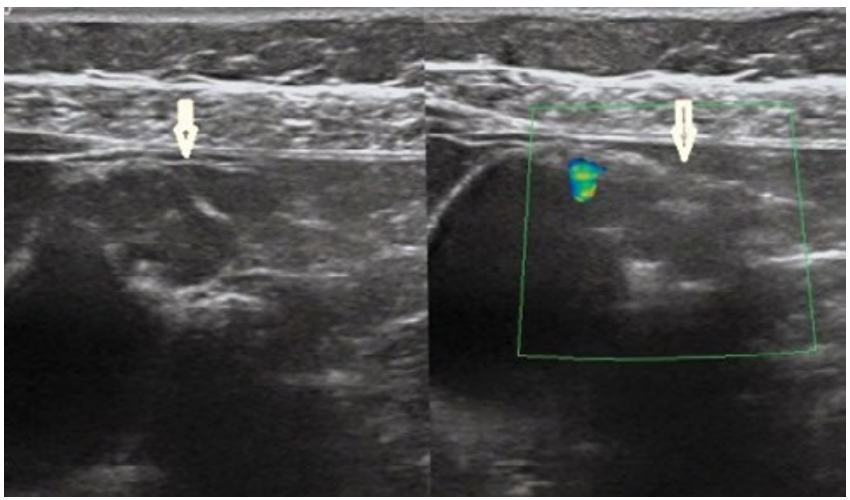

Fig. 6. Another example of adenomyomatosis in the gallbladder fundus visualized with a linear transducer. The Rokitansky-Aschoff sinuses are clearly seen

in mind that the cystic duct may be long and tortuous, which will pose a real challenge in such cases (Fig. 8). Horizontal position of the gallbladder at the level of the costal arch will pose another imaging difficulty (Fig. 9). This is a situation when the gallbladder walls are positioned least favorably, i.e. parallel to the ultrasound beam. This will require applying the transducer at different sites along with adjusting patient's position and the optimal level of breath hold.

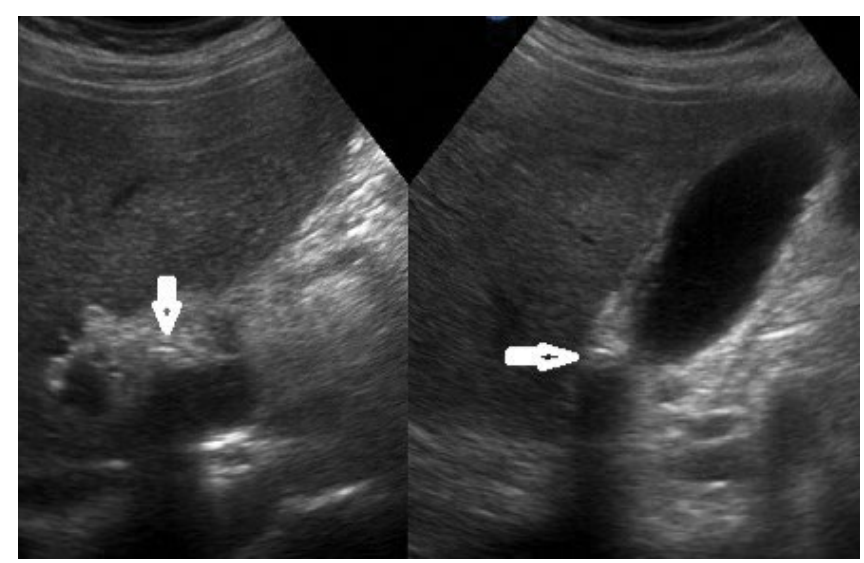

Fig. 7. The arrows indicate a small stone wedged in the neck of the gallbladder, which is difficult to visualize, on two cross-sections

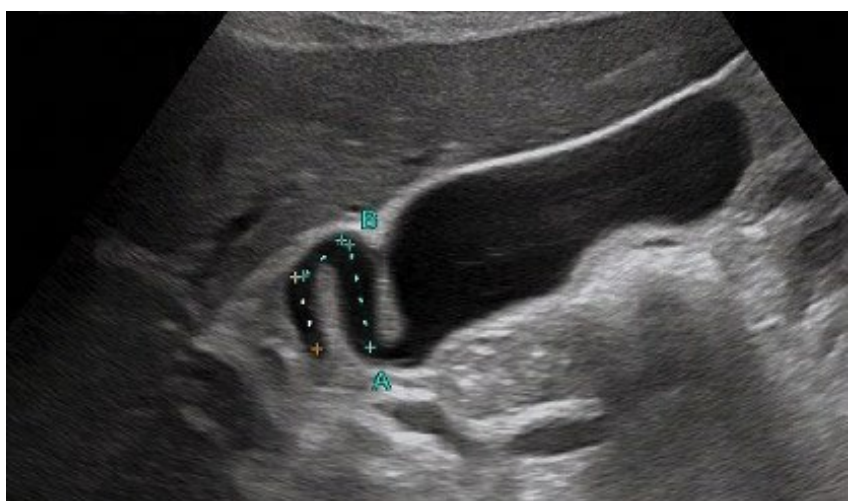

Fig. 8. A long (40 mm), bent cystic duct is seen on the sonogram

\section{Pseudolesions of the gallbladder}

Pseudolesions due to adherence of neighboring organs are another issue to discuss. The duodenal bulb may sometimes protrude into the gallbladder fundus, thereby mimicking a solid tumor, a liquid lesion or a stone (Fig. 10) ${ }^{(19)}$. In this situation, it is worth resuming gallbladder assessment as the bulb may shrink during this time and expose the fundus. In the case of further doubts, an intake of a glass of water 


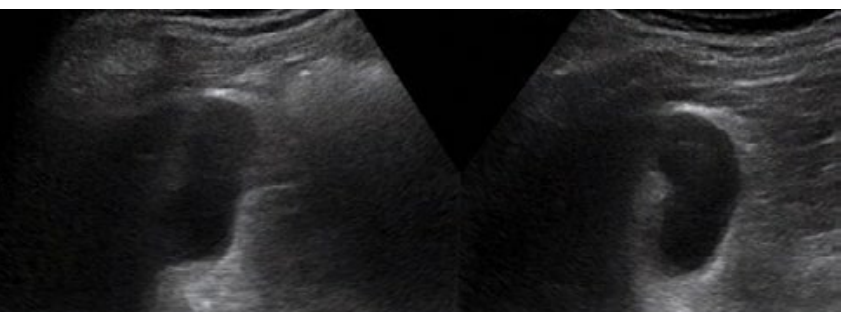

Fig. 9. Difficult gallbladder assessment due to its horizontal position at the level of the costal arch

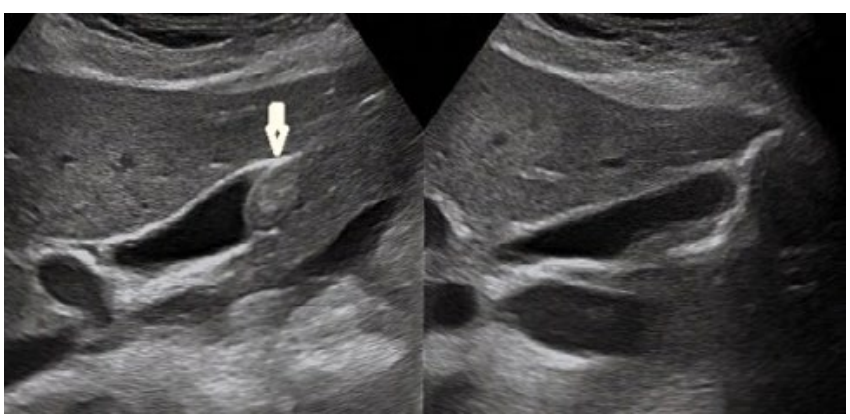

Fig. 10. Divided sonogram. The arrow on the left points to a pseudotumor of the gallbladder fundus due to duodenal bulb compression. After a while the entire gallbladder fundus was visible, as can be seen on the right side of the image

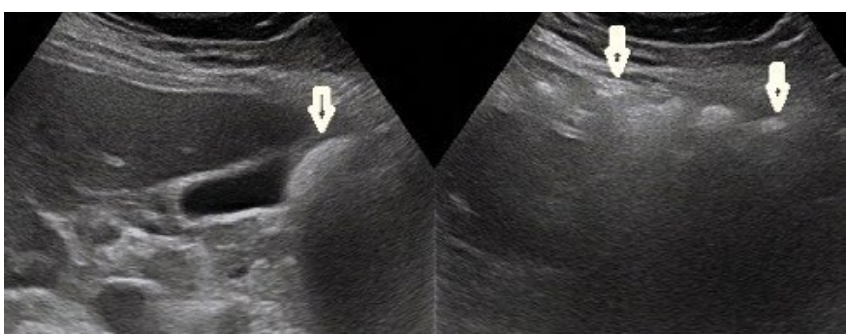

Fig. 11. Divided sonogram. The left-sided arrow indicates a lesion generating dirty shadow in the field of the gallbladder fundus. A segment of transverse colon with accentuated haustration (arrows), which is the cause of this acoustic phenomenon, is seen on the right side of sonogram

by the patient helps resolve the situation. The presence of fluid, often accompanied by duodenal gas, ultimately helps make a correct diagnosis.

The transverse colon filled with gas or stool may also mimic stones in the gallbladder fundus. Gas collections in the intestine cause the so-called dirty acoustic shadow. If this occurs, the transducer should be positioned in the long axis of the intestine, contributing to the visualization of the haustration of the transverse colon (Fig. 11).

\section{Measurement of gallbladder lesions}

The examples in section 1 indicate that a reliable measurement of the thickness of the gallbladder wall is only possible in the hepatic wall. It is advisable to measure it on an enlarged sonogram using the zoom function (Fig. 12).

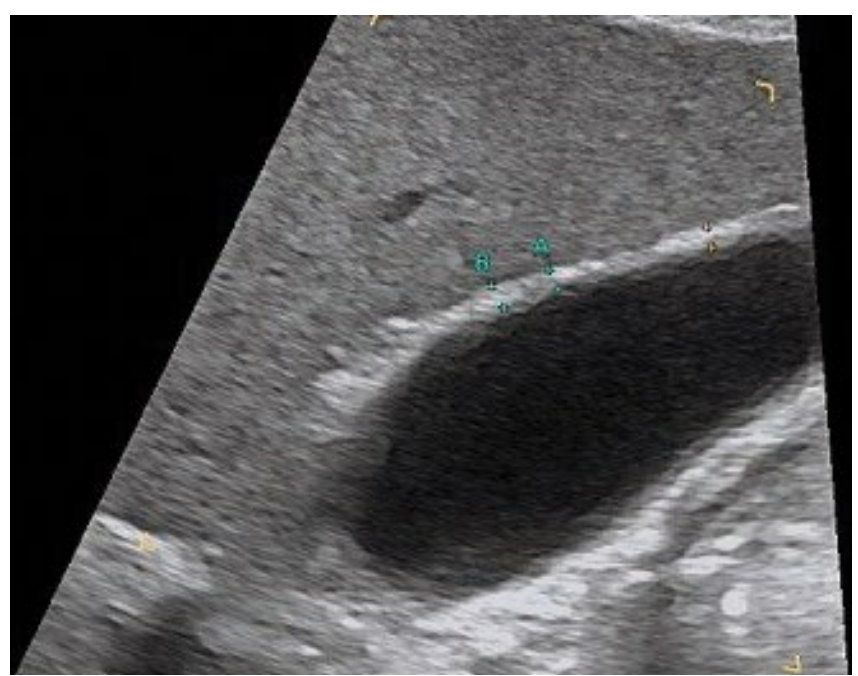

Fig. 12. The measurement of the actual gallbladder wall thickness is only possible on the hepatic wall

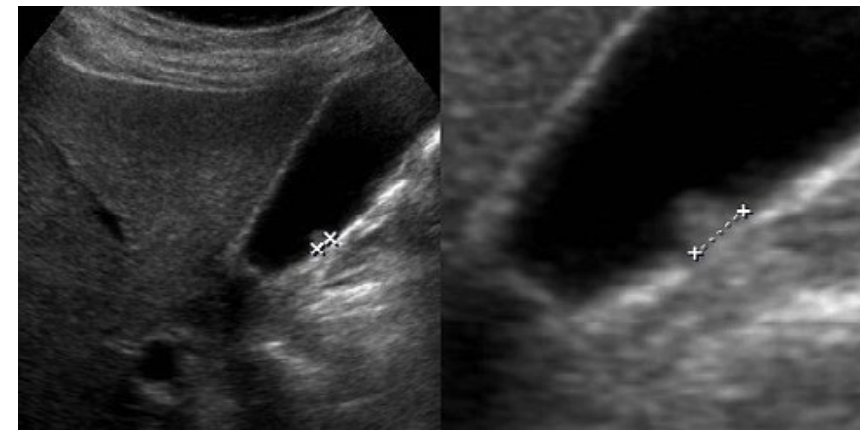

Fig. 13. Divided sonogram. A non-enlarged image of a polyp is seen on the left. The same polyp in a zoomed image on the right. The difference is the size is $1.5 \mathrm{~mm}$

The measurements are often performed using images obtained with a convex transducer (usually in one crosssection), especially in the case of polyps. This is not a precise method, as documented in Fig. 13. In such cases, it is worth zooming the image to assess the lesion in two dimensions (Fig. 14). Effort should be made to visualize the lesion in the largest possible dimensions as polypoid formations may be multi-shaped (Fig. 15). This is important due to the management strategy in gallbladder polyps. Resection is recommended for polyps $\geq 10 \mathrm{~mm}$ as they significantly increase the risk of dysplasia or cancer ${ }^{(2-4,20,21)}$. An enlarged image allows tracking the polyp's behavior over time with greater precision. According to Sun et al. ${ }^{(21)}$, growth of $\geq 3 \mathrm{~mm}$ in 6 months may be an indication for cholecystectomy. An enlarged sonogram may be used to search for smaller, often multiple, lesions. It is recommended that ultrasound surveillance of lesions is performed by the same physician.

\section{Lesion mobility assessment}

Each detected gallbladder lesion should be assessed for mobility as this allows for accurate diagnosis in most cases. Mobility is typically shown by deposits, a mass of biliary sludge, parasites and gas. A typical supine or left oblique position may be 


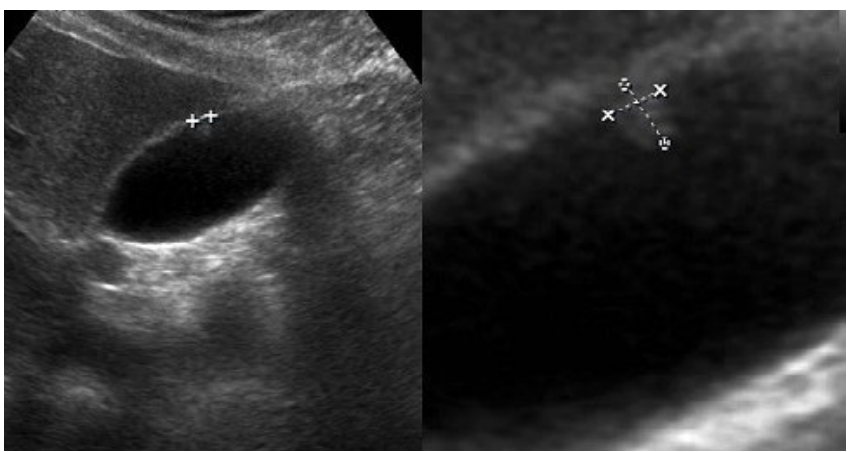

Fig. 14. Divided sonogram. The dimensions of the same polyp in a non-zoomed image on the left and in a zoomed image on the right

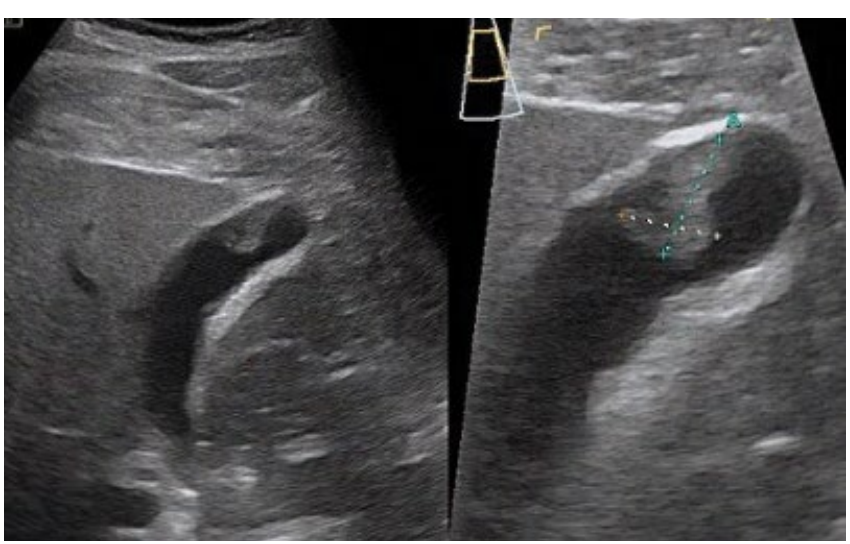

Fig. 15. Divided sonogram. Accurate assessment of shape and size of a gallbladder adenoma (right) is possible only using an enlarged image

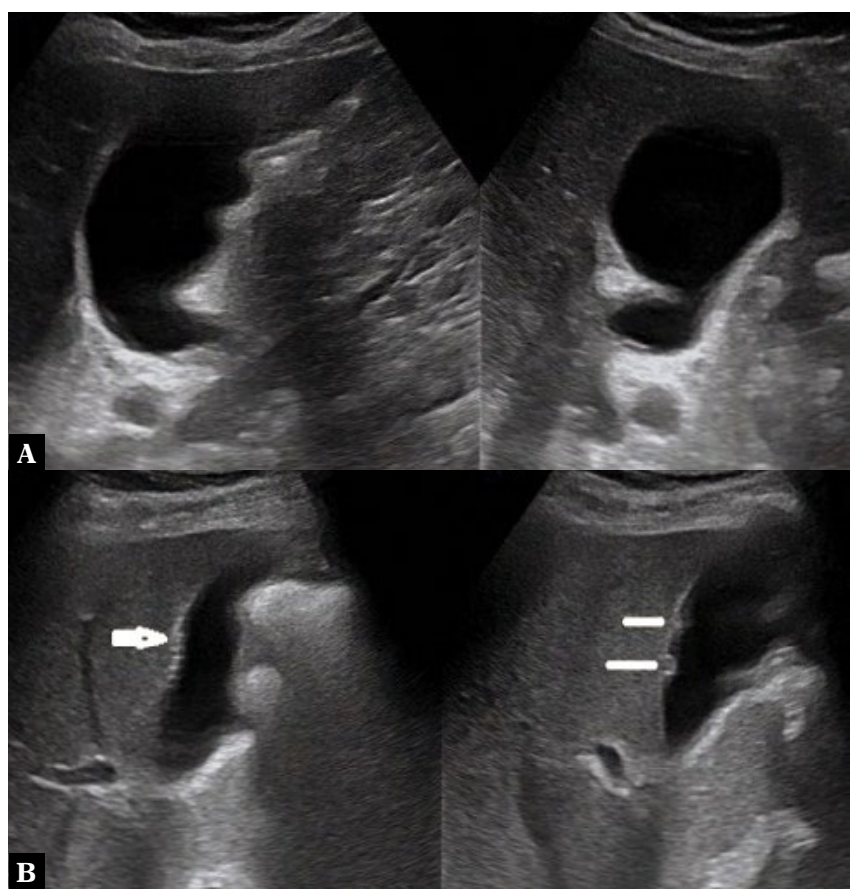

Fig. 16. Gallbladder. A. An image obtained in two oblique projections in supine position. Stones cannot be seen in these projections. B. The same gallbladder. Microstones were observed only in the right oblique position

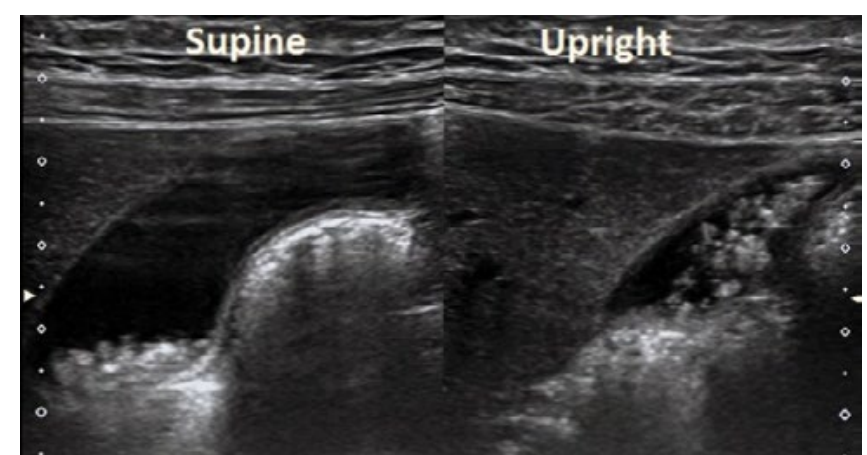

Fig. 17. Variable location of gallbladder microstones in a supine and upright position

associated with difficulties in detecting microcholelithiasis adhering to the wall adjacent to the duodenum, which is often filled with gas generating bright reflections. Right oblique position is useful in such cases. This allows for visualizing small deposits on the hepatic background and for a more reliable estimation of their number (Fig. $16 \mathrm{~A}$ and Fig. 16 B).

Another issue associated with gallstones in the gallbladder is their behavior depending on body position during scanning. Cholesterol stones account for a vast majority, i.e. $75 \%$, of biliary stones. Since their specific gravity is lower than that of bile, they migrate to the fundus of the gallbladder, which is often the highest part of this organ, when in upright position. Figure 17 shows gallbladder stone migration upon changing patient's position from a supine to upright position. Providing this information to patients should prevent them from lying down within an hour after a meal to avoid stone migration into the neck upon shrinking of the gallbladder. This relationship between stone location and body position is a common cause of biliary colic in the evening or at night.

Changes in position can even affect the gallbladder itself, which results from its faulty attachment to the liver (Fig. $18 \mathrm{~A}$ and Fig. 18 B). A mobile gallbladder, which is also referred to as a floating gallbladder, will be prone to torsion. This complication usually occurs in emaciated, elderly females. This is a serious life-threatening condition ${ }^{(22-24)}$.

\section{Vascularization of lesions}

The introduction of high-sensitivity blood flow imaging methods is an additional important factor supporting gallbladder ultrasound diagnosis. The degree of vascularization of lesions detected in the gallbladder and its walls should be assessed in various pathologies during each examination. Color Doppler should be set at slow blood flow, i.e. $2-10 \mathrm{~cm} / \mathrm{s}^{(2)}$.

This modality is recommended in the following situations:

- assessment of the degree of gallbladder wall congestion and/or ischemia in cholecystitis ${ }^{(25)}$;

- differentiation between pseudopolyps and true polyps (it is often possible to visualize vasculature in the latter $\left.{ }^{(26)}\right)$ (Fig. 19);

- detecting pathological vascularization in gallbladder cancer and invaded tissues ${ }^{(26-28)}$ (Fig. 20); 

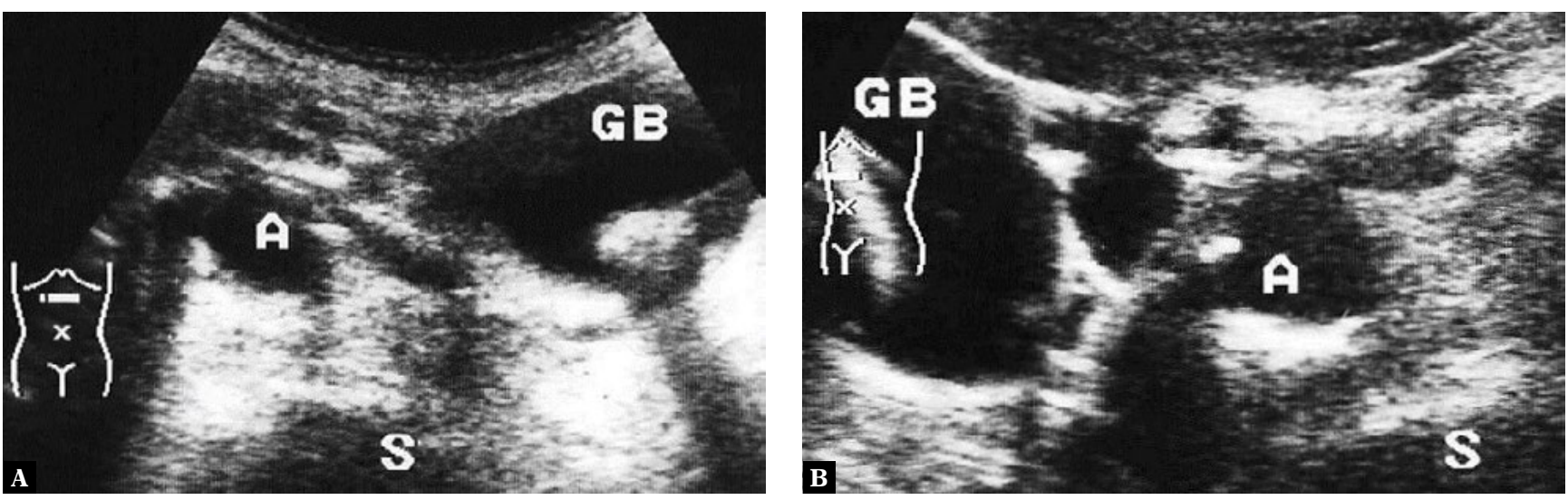

Fig. 18. A floating gallbladder with a stone. A. In a supine position, the gallbladder (GB) is located to the left of the aorta (A). S-Spine. B. The same gallbladder in the position on the right side. The gallbladder $(G B)$ migrated to the right of the aorta (A)

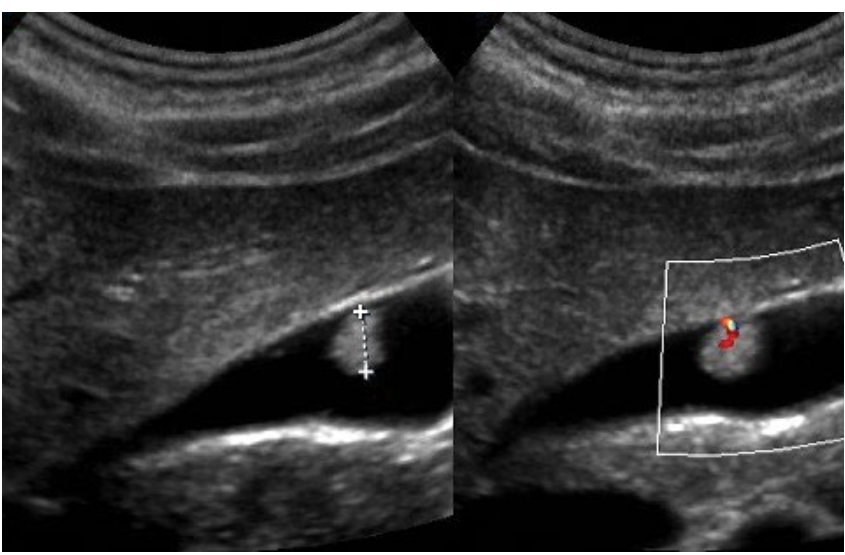

Fig. 19. Divided sonogram. Size and vascular pattern of a gallbladder adenoma

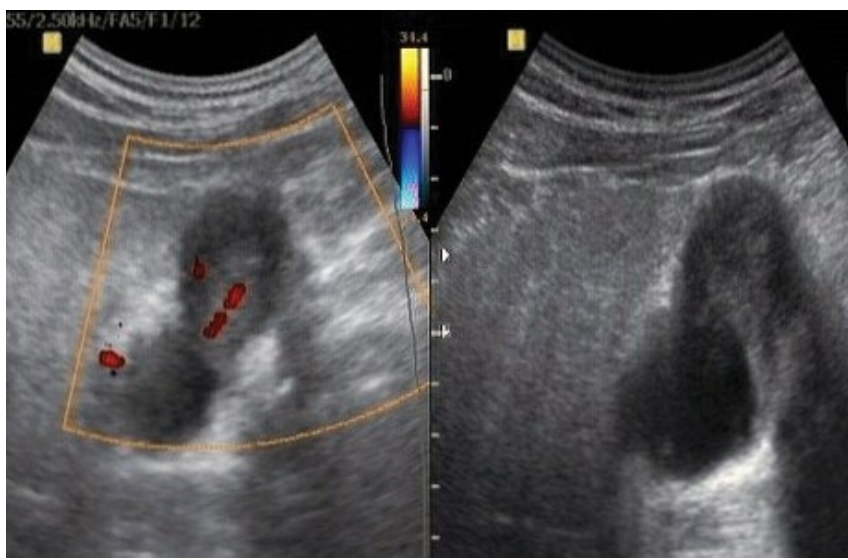

Fig. 20. Divided sonogram. Vascularized gallbladder cancer mimicking a mass of biliary sludge

- diagnosis of gallbladder varices ${ }^{(29-31)}$ (Fig. $21 \mathrm{~A}$ and Fig. 21 B);

- visualization of a twinkling artifact in focal adenomyomatosis of the gallbladder ${ }^{(1,26)}$ (Fig. 4 B and Fig. 6);

- differentiation between a mass of biliary sludge and a solid tumor in the gallbladder ${ }^{(26)}$.

- attempt to locate the site of gallbladder perforation ${ }^{(32)}$.
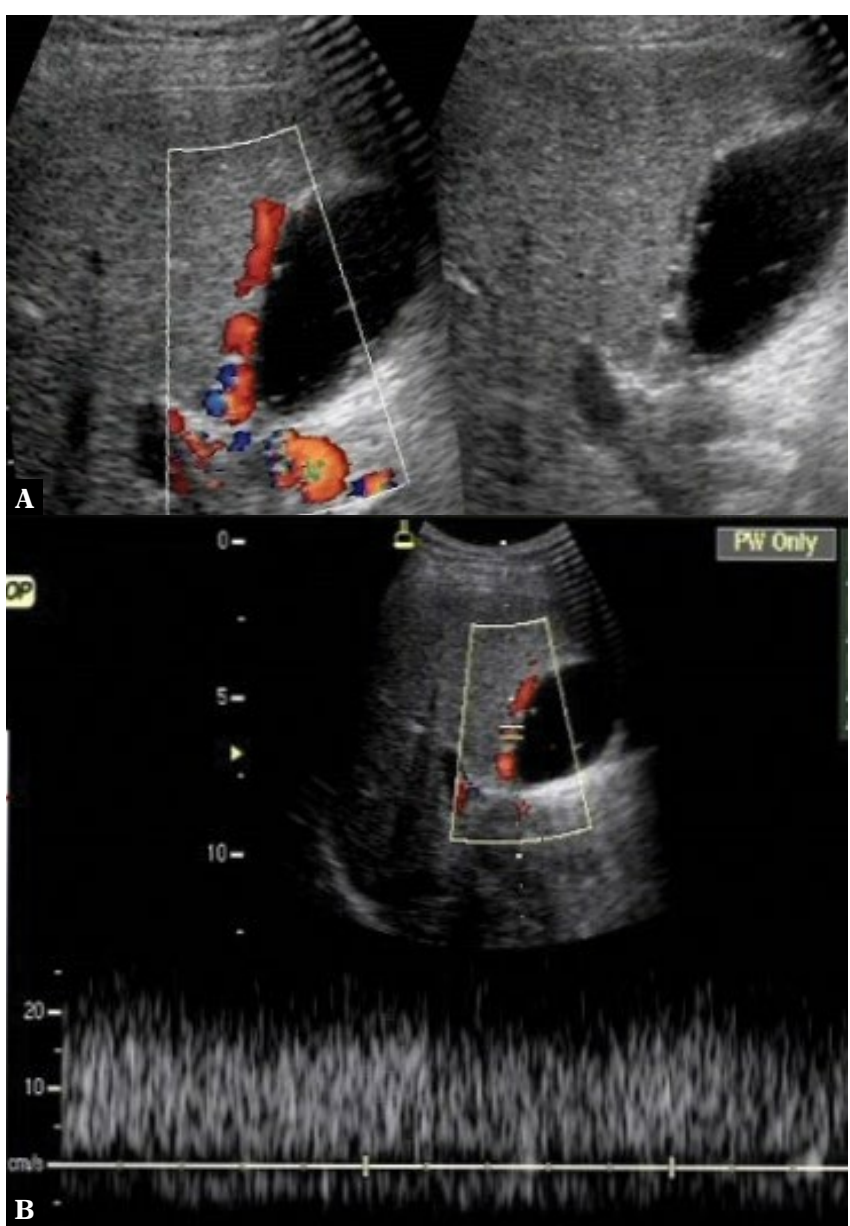

Fig. 21. A. Portal vein thrombosis in cirrhosis. Gallbladder wall blood vessels were visualized with Color Doppler. B. Pulsed Wave Doppler showed venous blood flow in these vessels

\section{Conclusion}

The issues presented in this paper are only a fraction of problems faced by an ultrasound operator in the field of gallbladder diagnostic imaging. However, the proposed ultrasound approaches should help solve some of these problems in everyday practice. 


\section{Conflict of interest}

The authors do not report any financial or personal connections with other persons or organizations, which might negatively affect the contents of this publication and/or claim authorship rights to this publication.

\section{References}

1. Joo I, Lee JY, Kim JH, Kim SJ, Kim MA, Han JK et al.: Differentiation of adenomyomatosis of the gallbladder from early-stage, wall-thickeningtype gallbladder cancer using high-resolution ultrasound. Eur Radiol 2013; 23: 730-738.

2. Badea R, Zaro R, Opincariu I, Chiorean L: Ultrasonad in the examination of the gallbladder a holistic approach: grey scale, Doppler, CEUS, elastography, and 3D. Med Ultrason 2014; 16: 345-355.

3. Wennmacker SZ, Lamberts MP, Di Martino M, Drenth JP, Gurusama KS, van Laarhoven CJ: Transabdominal ultrasound and ultrasound for diagnosis of gallbladder polyps. Cochrane Database Syst Rev 2018, doi 10.1002/14651858.CD012233.pub2.

4. Sugiyama M, Atomi Y, Yamato T: Endoscopic ultrasonography for differential diagnosis of polypoid gallbladder lesions: analysis in surgical and follow up series. Gut 2000; 46: 250-254.

5. Gerstenmaier JF, Hoang KN, Gibson RN: Contrast-enhanced ultrasound disease: a pictorial review. Abdom Radiol 2016; 41: 1640-1652.

6. Sugimoto M, Takagi T, Suzuki R, Konno N, Asama H, Watanabe K et al.: Contrast-enhanced harmonic endoscopic ultrasonography in gallbladder cancer and pancreatic cancer. Fukushima J Med Sci 2017; 63: 39-45.

7. Yuan HX, Wang WP, Guan PS, Lin LW, Wen JX, Yu Q et al.: Contrastenhanced ultrasonography in differential diagnosis of focal gallbladder andenomyomatosis and gallbladder cancer. Clin Hemorheol Microcirc 2018; 70: 201-211.

8. Bea JS, Kim SH, Kang HJ, Kim H, Ryu JK, Jang JY et al.: Quantitative contrast-enhanced helps differentiating neoplastic vs non-neoplastic gallbladder polyps. Eur Radiol 2019; 29: 3772-3781.

9. Noble JA, Boukerroui D: Ultrasound image segmentation: a survey. IEEE Trans Med Imaging 2006; 25: 987-1010.

10. Carvalho FF, Bensebaa K: Automatic localization and segmentation of cholelithiasis crystals in ultrasound images. Conf Proc IEEE Eng Med Soc 2010; 2010: 4727-4730.

11. Lian J, Ma Y, Ma Y, Shi B, Liu J, Yang Z et al.: Automatic gallbladder and gallstone regions segmentation in ultrasound image. Int J Comput Assist Radiol Surg 2017; 12: 553-568.

12. Zargar SA, Khuroo MS, Mahajan R, Jan GM, Shah P: US-guided fine-needle aspiration biopsy of gallbladder masses. Radiology 1991; 179: 275-278.

13. Rana C, Krishnani N, Kumari N: Ultrasound-guided fine needle aspiration cytology of gallbladder lesions: a study of 596 cases. Cytopathology 2016; 27: 398-406.

14. Chantarojanasiri T, Hirooka Y, Kawashima H, Ohno E, Kongkam P, Goto $\mathrm{H}$ : The role of endoscopic ultrasound in the diagnosis of gallbladder diseases. J Med Ultrason (2001) 2017; 44: 63-70.

15. Luk SW, Irani S, Krishnamoorthi R, Wong Lau JY, Wai Ng EK, Teoh AY: Endoscopic ultrasound-guided gallbladder drainage versus percutaneous cholecystostomy for high risk surgical patients with acute cholecystitis: a systemic review and meta-analysis. Endoscopy 2019; 51: 722-732.
16. Mori Y, Itoi T, Baron TH, Takada T, Strasberg SM, Pitt HA et al.: Tokyo Guidelines 2018: management strategies of gallbladder drainage in patients with acute cholecystitis (with video). J Hepatobiliary Pancreat Sci 2018; 25: 87-95.

17. Hertzberg BS, Middleton WD: Ultrasound: the requisites. Elsevier, Philadelphia 2016.

18. Golse N, Lewin M, Rode A, Sebagh, Mabrut JY: Gallbladder adenomyomatosis: diagnosis and management. J Vasc Surg 2017; 154: 345-353.

19. Walas MK, Skoczylas K, Gierbliński I: Standardy badań ultrasonograficznych Polskiego Towarzystwa Ultrasonograficznego - aktualizacja. Badanie wątroby, pęcherzyka żółciowego i dróg żółciowych. J Ultrason 2012; 12: 428-445.

20. Sarkut P, Kilicturgay S, Ozer A, Ozturk E, Yilmazlar T: Gallbladder polyps: factors affecting surgical decision. World J Gastroenterol 2013; 19: 4526-4530.

21. Sun Y, Yang Z, Lan X, Tan H: Neoplastic polyps in gallbladder: a retrospective study to determine risk factors and treatment strategy for gallbladder polyps. Hepatobiliary Surg Nutr 2019; 8: 219-227.

22. Safadi RR, Abu-Yousef MM, Farah AS, al-Jurf AS, Shirazi SS, Brown BP: Preoperative sonographic diagnosis of gallbladder torsion: report of two cases. J Ultrasound Med 1993; 12: 296-298.

23. Lee SE, Choi YS, Kim BJ: Torsion of gallbladder in pregnancy. J Korean Surg Soc 2013; 85: 302-304.

24. Alkhalili E, Bencsath K: Gallbladder torsion with acute cholecystitis and necrosis. BMJ Case Rep 2014, doi: 10.1136/bcr-2014-204917.

25. Uggowitzer M, Kugler C, Schramayer G, Kammerhuber F, Gröll R, Hausegger KA et al.: Sonography of acute cholecystitis: comparison color and power Doppler sonography in detecting a hypervascularized gallbladder wall. AJR Am J Roentgenol 1997; 168: 707-712.

26. Bang SH, Lee JY, Woo H, Joo I, Lee ES, Han JK et al.: Differentiating between adenomyomatosis and gallbladder cancer: revisiting a comparative study of high-resolution ultrasound, multidetector CT and MR imaging. Korean J Radiol 2014; 15: 226-234.

27. Li D: Color Doppler flow imaging in gallbladder tumors. Zhonghua Yi Xue Za Zhi 1992; 72: 394-396.

28. Hirooka Y, Naitoh Y, Goto H, Furukawa T, Ito A, Hayakawa T: Differential diagnosis of gallbladder masses using color Doppler ultrasonography. J Gastroenterol Hepatol 1996; 11: 840-846.

29. Chawla Y, Dilawari JB, Katariya S: Gallbladder varices in portal vein thrombosis. AJR Am J Roentgenol 1994; 162: 643-645.

30. Sato A, Ishida H, Yagisawa H, Kurokawa H: Gallbladder varices. J Med Ultrason (2001) 2006; 33: 257.

31. Gnerre J, Sun Y, Jedynak A, Gilet A: Case report: gallbladder varices in a patient with portal vein thrombosis secondary to hepatocellular carcinoma. J Radiol Case Rep 2016; 10; 22-28.

32. Hongo M, Ishida H, Naganuma H, Yoshioka H, Kasuya T, Niwa M: A case of gallbladder perforation detecting by sonography after blunt abdominal trauma. J Clin Ultrasound 2014; 42: 301-303. 